\title{
Development of Impedimetric Biosensor for Total Cholesterol Estimation Based on Polypyrrole and Platinum Nanoparticle Multi Layer Nanocomposite
}

\author{
K. Singh ${ }^{1}$, Ruchika Chauhan ${ }^{2}$, Pratima R. Solanki ${ }^{2}$, Tinku Basu ${ }^{2 *}$ \\ ${ }^{1}$ Amity School of Engineering and Technology, Amity University, Noida, India \\ ${ }^{2}$ Amity Institute of Nano Technology, Amity University, Noida, India \\ Email: "tbasu@amity.edu, basu002@yahoo.com
}

Received November 5, 2013; revised December 8, 2013; accepted December 21, 2013

Copyright (C) $2013 \mathrm{~K}$. Singh et al. This is an open access article distributed under the Creative Commons Attribution License, which permits unrestricted use, distribution, and reproduction in any medium, provided the original work is properly cited.

\begin{abstract}
A novel impedimetric biosensor was fabricated for total cholesterol sensing based on platinum nanoparticle and polypyrrole multilayer nanocomposite electrode. The Pt nanoparticles (PtNP) electrochemically deposited between two polypyrrole layers on indium tin oxide (ITO) glass plates (PtNP/PPY/ITO) have offered high-electroactive surface area and favourable microenvironment for immobilization of cholesterol esterase (ChEt) and cholesterol oxidase (ChOx) resulting in enhanced electron transfer between the enzyme system and the electrode. Impedimetric response studies of the ChEt-ChOx/PtNP/ITO nanobioelectrode exhibit improved linearity $\left(2.5 \times 10^{-4}\right.$ to $\left.6.5 \times 10^{-3} \mathrm{M} / \mathrm{l}\right)$, low detection limit $\left(2.5 \times 10^{-4} \mathrm{M} / \mathrm{l}\right)$, fast response time $(25 \mathrm{~s})$, high sensitivity $\left(196 \Omega / \mathrm{mM} / \mathrm{cm}^{-2}\right)$ and a low value of the Michaelis-Menten constant $(\mathrm{Km}, 0.2 \mathrm{M} / \mathrm{l})$ with a regression coefficient of 0.997 .
\end{abstract}

Keywords: Polypyrrole; Cholesterol Biosensor; Impedance Spectroscopy; Charge Transfer Resistance

\section{Introduction}

Innovations in the field of electrochemical biosensors' matrix are of much importance nowadays for the development of highly sensitive, selective, reliable and low cost biosensors for the clinical diagnosis [1]. The metal nanoparticles have been widely exploited due to their ability as electrode modification materials to enhance the efficiency of electrochemical biosensor [2-4]. This can be attributed to the ability to design novel sensing systems and enhance the performance of bioanalytical assays ${ }^{1}$. Pt is a well-known catalyst that has a high catalytic activity for hydrogen peroxide electro oxidation [5-7]. Pt nanoparticles (PtNP) on the electronically conducting polypyrrole can enhance conduction and charge transport properties compared to the conventionally synthesized polypyrrole film [8-10]. PtNP possess high surface area, nontoxicity, good biocompatibility and chemical stability, and also show fast electron communication features which provide a desirable microenvironment to enzyme for

\footnotetext{
*Corresponding author.

${ }^{1}$ http://www.wiley-vch.de/books/sample/3527328416_c01.pdf.
}

the direct electron transfer between the enzyme's active sites and the electrode. The PtNP not only retain the bioactivity of the immobilized enzyme but also enhance the sensing characteristics such as sensitivity, selectivity and low detection limit of the fabricated amperometric enzymatic biosensors [11]. The PtNP have the advantages of easy electrochemical synthesis and reproducible preparation, long-term stability and ability to incorporate enzyme successfully via covalent bonding by using carbodiimide chemistry i.e. $\mathrm{N}$-hydroxysuccinimide (NHS) and $N$-ethyl- $N$-(3-dimethylaminopropyl carbodiimide) (EDC). Chen et al. have developed a glucose biosensor based on conducting chitosan decorated with PtNP with a response time of $5 \mathrm{~s}$ [12].

Human serum contains a mixture of free and esterified cholesterol, both of which are measured to determine the total cholesterol level [13]. The determination of cholesterol level is of importance in clinical diagnosis [14] because of diseases such as coronary heart disease, myocardial infarction and arteriosclerosis $[15,16]$. It is important to note that $70 \%$ of the total blood cholesterol exists in ester form and $30 \%$ in free form. But the re- 
search work on total cholesterol estimation is limited. Most research work till date is focused on the estimation of free cholesterol [17-20]. Singh et al. have utilized conducting polymers (CP) for the total cholesterol determination [21-23]. However, these biosensors have been found to have low sensitivity $\left(7.5 \times 10^{-4} \mathrm{nA} / \mathrm{mg} / \mathrm{dl}\right)$ and a high response time, like $240 \mathrm{~s}$. Li et al. have fabricated screen-printed MWCNT polycarbonate electrode to investigate total cholesterol and found that the CNT-modified biosensor offers a reliable calibration profile [24]. Solanki et al. have immobilized cholesterol esterase (ChEt) and $\mathrm{ChOx}$ via glutaraldehyde as a cross-linker onto sol-gel-derived silica/chitosan/MWCNT-based nanobiocomposite electrode deposited onto ITO for the determination of esterified cholesterol [25]. This bioelectrode shows a response time of $10 \mathrm{~s}$, sensitivity of 3.8 $\mu \mathrm{A} / \mathrm{mM}$, and shelf life of about 10 weeks for the estimation of cholesterol oleate. The gold nanowire-modified microfluidic-based amperometric total cholesterol bioelectrode has linearity of 1 to $6 \mathrm{mM} / 1$ [26]. Arya et al. have reported self-assembled monolayer-based cholesterol sensors and found linearity of 10 to $500 \mathrm{mg} / \mathrm{dl}$ $[27,28]$. Basu et al. have fabricated a nanocomposite electrode comprising of polypyrrole (PPY) and carboxy functionalized multiwalled carbon nanotubes (MWCNT) to estimate total cholesterol in the range of $4 \times 10^{-4}$ to $6.5 \times 10^{-3} \mathrm{M} / 1$ and they have used to determine cholesterol in blood serum samples [29]. Basu et al. have also developed a reusable total cholesterol electrode based on nano structured conducting polyaniline [30].

Electrochemical impedance spectroscopy (EIS) has recently been important as a nondestructive, sensitive and efficient means for characterization of electrical properties of materials in biological interfaces [31,32]. In this study, an attempt has been made to develop PtNP and PPY based electrodeposited tri-layer nanocomposite film and the same has been evaluated as a transducer matrix for total cholesterol estimation using impedance spectroscopy. The change in impedance of nanobiocomposite electrodes with the change of different concentration of cholesterol oleate is used as a measure of biosensor performance. To the best of our knowledge, electrochemical impedance spectroscopy, as a measure of total cholesterol estimation, has not been exploited till today. The novelty of this study lies on the ease of fabrication of PtNP based PPY multilayer nanocomposite electrode which provides enzyme friendly environment, non-destructive measurement technique for total cholesterol, high sensitivity, reproducibility and shelf life of the biosensor for total cholesterol estimation.

\section{Experimental}

\subsection{Reagent}

Hexa Chloroplatinic Acid $\left(\mathrm{H}_{2} \mathrm{PtCl}_{6}\right)(\mathrm{Pt}, 40 \%), N$-hy- droxysuccinimide (NHS), $\mathrm{N}$-ethyl- $\mathrm{N}$-(3-dimethylaminopropyl carbodiimide) (EDC), Cholesterol oleate (98\%), cholesterol esterase (EC 3.1.1.13, pseudomonas species) with specific activity as $165 \mathrm{U} / \mathrm{mg}$ and cholesterol oxidase (EC 1.1.36 Pseudomonas fluorescens) with specific activity of $24 \mathrm{U} / \mathrm{mg}$ have been purchased from SigmaAldrich (USA). Pyrrole (PY) (M.W: 67.09) from spectrochem was double distilled prior to polymerization. All other chemicals are of analytical grade and have been used without further purification and the solutions are prepared in deionized water. Cholesterol oleate (400 $\mathrm{mg} / \mathrm{dl}$ ) is first dissolved in $1 \%$ polidocanol (Brij) as a surfactant by heating and gentle stirring resulting in clear and colourless suspension and final volume is made by addition of $0.9 \% \mathrm{NaCl}$ solution.

\subsection{Instrumentation}

The Fourier transform infrared spectra for PPY/ITO, PtNP/PPY/ITO electrodes and ChEt-ChOx/PtNP/PPY/ ITO nanobioelectrodes have been recorded on Perkin Elmer Spectrophotometer BX-1 in the frequency range, 405 - $4000 \mathrm{~cm}^{-1}$. Surface morphologies of PPY/ITO, PtNP/PPY/ITO electrodes and ChOx-ChEt/PtNP/PPY/ ITO nanobioelectrode have been investigated by scanning electron microscope (LEO Model). Electrochemical impedance spectroscopy (EIS), cyclic voltammetry (CV) and differential pulse voltammetry study (DPV) have been conducted in phosphate buffer $(50 \mathrm{mM}, 0.9 \% \mathrm{NaCl})$ containing $5 \mathrm{mM}\left[\mathrm{Fe}(\mathrm{CN})_{6}\right]^{3-/ 4-}$ in a three-electrodes cell consisting of $\mathrm{Ag} / \mathrm{AgCl}$ as reference, platinum (Pt) as counter electrode and ITO as a working electrode $(0.25$ $\mathrm{cm}^{2}$ ) using Potentiostat/Glavanostat (Princeton Applied Research, model No. 273).

\subsection{Preparation of ChEt-ChOx/PtNP/PPY/ITO Nano-Bioelectrode}

The PtNP/PPY/ITO nano composite electrode was fabricated in three steps. In the first step, pyrrole was electropolymerised onto ITO coated glass plates (PPY/ITO) in a three-electrode cell containing $0.1 \mathrm{M}$ pyrrole and $0.1 \mathrm{M}$ PTS (p-toluene sulfonic acid) solution in deionized water by chronopotentiometry using a Potentiostat/Galvanostat. In second step, the PPY/ITO electrode was dipped in 0.8 $\mathrm{mM}$ hexa chloroplatinic acid solution. The Pt nanoparticle (PtNP) was deposited on the PPY/ITO electrode using chronoamperommetry technique. In final step, the PtNP decorated PPY/ITO electrode was again dipped in $0.1 \mathrm{M}$ pyrrole solution in order to deposit another thin layer of PPY using chronopotentiometry technique to fabricate a try layer nano composite of PPY/PtNP/PPY/ ITO electrode which is defined as PtNP/PPY/ITO in the manuscript. The fabrication process of nano bioelectrode 
is shown in Scheme 1. The deposition potential and concentration of hexa chloroplatonic acid solution, and deposition time of each layer were varied to achieve the optimum electrochemical properties of PtNP/PPY/ITO nano composite electrode. The PtNP/PPY/ITO nano composite electrode was cleaned with deionized water. The enzymes (ChOx and ChEt (1:1)) were covalently immobilized onto the PtNP/PPY/ITO nano composite electrode using EDC as the coupling agent and NHS as the activator. For enzyme immobilization, the optimal binding was achieved when $30 \mu \mathrm{l}$ of solution of $5 \mu \mathrm{g}$ of enzymes (1:1) mixed with $0.4 \mathrm{M}$ EDC and 0.1 M NHS was dropped on $1 \mathrm{~cm}^{2}$ of PtNP/PPY/ITO nano composite electrode and kept in a humid chamber for $3 \mathrm{~h}$. Thus, fabricated ChEt-ChOx/PtNP/PPY/ITO (Scheme 1) was then washed with phosphate buffer saline (PBS) solution $(50 \mathrm{mM}, 0.9 \% \mathrm{NaCl}, \mathrm{pH} 7.0)$ to remove any unbound enzyme and was stored at $4^{\circ} \mathrm{C}$ when not in use.

\section{Results and Discussion}

\subsection{Optimization of the Fabrication Process of PtNP/PPY/ITO Nano Composite Electrode}

The PtNP/PPY/ITO nano composite film has been fabricated on ITO electrode using both chronoamperometric and chronopotentiometric techniques. The electronic conductivity of the nano composite film has been optimized by varying concentration of $\mathrm{H}_{2} \mathrm{PtCl}_{6}$, deposition potential of $\mathrm{H}_{2} \mathrm{PtCl}_{6}$ and multilayer deposition time. After the deposition of a thin layer of polypyrrole on ITO, PtNP has been deposited using chronoamperometric technique on PPY/ITO electrode. The optimum electronic conductivity of the nano composite film (PtNP/ PPY/ITO) and minimum size distribution have been achieved at a concentration of $0.8 \mathrm{mM} / 1$ of $\mathrm{H}_{2} \mathrm{PtCl}_{6}$. The Figure 1A represents cyclic voltamommetry of PtNP/ PPY/ITO electrodes, fabricated by varying electrodeposition potential of $\mathrm{H}_{2} \mathrm{PtCl}_{6}$, in phosphate buffer (50 $\mathrm{mM}, \mathrm{pH} 7.0)$ containing $5 \mathrm{mM}\left[\mathrm{Fe}(\mathrm{CN})_{6}\right]^{3-/ 4-}$ in the range of $-300 \mathrm{mV}$ to $1 \mathrm{~V}$. The Figure $1 \mathrm{~A}(\mathrm{I})$ demonstrates the variation of anodic peak current with deposition potential of $\mathrm{H}_{2} \mathrm{PtCl}_{6}$ and optimum result has been obtained at $-300 \mathrm{mV}$. Therefore, PtNP has been deposited at $-300 \mathrm{mV}$ for entire work.

The deposition time of each layer has been varied in order to achieve the optimum property of try layer nano composite film. The Figure 1B represents the cyclic voltammogram of PtNP/PPY/ITO at various deposition time. The Figure 1B: Inset shows the plot of anodic peak current vs deposition time. It has been noticed that maximum peak current has been obtained when deposi- tion time is 30,40 and $60 \mathrm{~s}$ for $1 \mathrm{st}$ layer of PPY, PtNP and 2nd layer of PPY respectively. However, inner layer of PPY is to improve the contact between the PtNP and

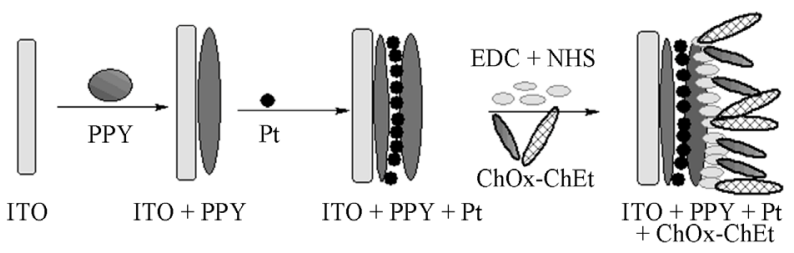

Scheme 1. Schematic diagram for fabrication of bioelectrode ChOx-ChEt/PtNP/PPY/ITO.
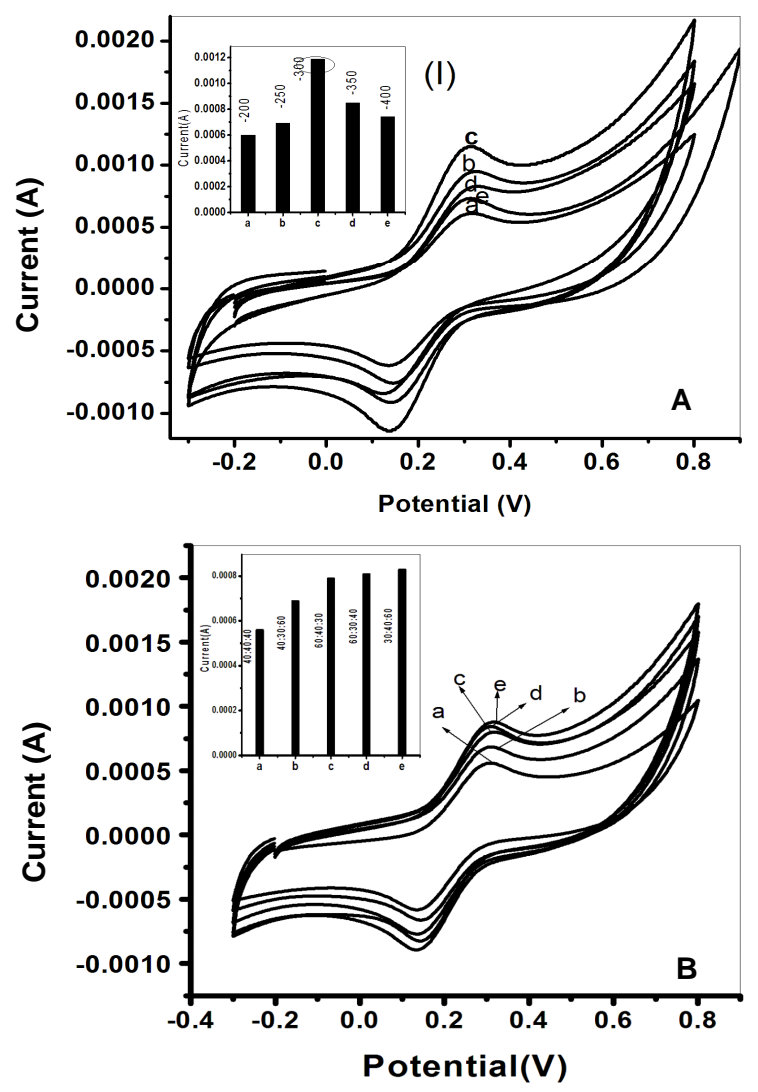

Figure 1. A. Cyclic voltammogram of PtNP/PPY/ITO electrodes fabricated by varying deposition potential of $\mathrm{H}_{2} \mathrm{PtCl}_{6}$. (a) $-200 \mathrm{mV}$; (b) $-250 \mathrm{mV}$; (c) $-300 \mathrm{mV}$; (d) $-350 \mathrm{mV}$; (e) $-400 \mathrm{mV}$; Inset 1(I): Plot of variation of anodic peak current vs deposition potential of $\mathrm{H}_{2} \mathrm{PtCl}_{6}$. B. Cyclic voltammogram of PtNP/PPY/ITO electrode fabricated by varying deposition time for each layer (a) 40:40:40; (b) 40:30:60; (c) 60:40:30; (d) 60:30:40; (e) 30:40:60; Inset a: plot of anodic peak current vs deposition time for various nano composite electrodes fabricated by varying the deposition time of each layer characterization of PtNP/PPY/ITO and ChOx-ChEt/ PtNP/PPY/ITO electrode.

the ITO electrode, so a thin inner layer of PPY is required.

\subsection{Characterization of PtNP/PPY/ITO and ChOx-ChEt/PtNP/PPY/ITO Electrode}

The morphology of PPY/ITO, PtNP/PPY/ITO and ChOx$\mathrm{ChEt} / \mathrm{PtNP} / \mathrm{PPY} / \mathrm{ITO}$ was studied by scanning electron 
microscope (SEM). The SEM images are shown in Figures 2A-C. The Figure $2 \mathrm{~A}$ shows that the bulk polymer tends to aggregate in large particles in the globular morphology which becomes more evident with spherical ball shapes. The PtNP, grown in between the PPY thin layers structure during electrodeposition, has been observed in the SEM image of PtNP/PPY/ITO (Figure 2B). The SEM micrograph shows that PtNP grown on PPY/ITO electrode (Figure 2B) exhibits a granular form like a ball structure along with few cylindrical rod-like structure arrayed in a disordered way. The size of the spherical nanoparticles varies from ca. 50 to $80 \mathrm{~nm}$ with average particle size of ca.70 $\mathrm{nm}$. Moreover, PtNP are seen to agglomerate due to high surface energy and strong inter atomic interactions. However, after the immobilization of ChEt and ChOx, the surface morphology of PtNP/PPY/ ITO film changes into well-arranged regular morphology and surface roughness decreases revealing that the enzymes are adsorbed onto PtNP/PPY/ITO (Figure 2C) via covalent bonding and electrostatic interactions. The SEM images of ChEt-ChOx/PtNP/PPY/ITO nanobio-electrode exhibit uniform distribution of the enzymes indicating that PtNP/PPY/ITO film provides a desired microenvironment for strong adsorption of enzymes.

Figure 3 demonstrates FTIR spectra of (a) PPY/ITO, (b) PtNP/PPY/ITO, (c) ChEt-ChOx/PtNP/PPY/ITO electrodes. The Figure 3(a) shows the characteristics absorption bands of polypyrrole. The peaks at $1580 \mathrm{~cm}^{-1}$ and $1470 \mathrm{~cm}^{-1}$ are due to the fundamental vibration of the pyrrole ring [33]. The peaks at $1105 \mathrm{~cm}^{-1}, 1055 \mathrm{~cm}^{-1}$ and $1320 \mathrm{~cm}^{-1}$ are attributed to the $=\mathrm{C}-\mathrm{H}$ in plane vibration [33]. The broad band at $1178 \mathrm{~cm}^{-1}$ may be assigned to $\mathrm{N}-\mathrm{C}$ stretching band (Nicho and $\mathrm{Hu}, 2000)$. All the characteristics peaks of PPY/ITO electrode are visible in the FTIR spectrum of PtNP/PPY/ITO (Figure 3(b)). The peak at $3416 \mathrm{~cm}^{-1}$ is attributed to $\mathrm{N}-\mathrm{H}$ stretch vibration. The band at $1320 \mathrm{~cm}^{-1}$ corresponds to $=\mathrm{C}-\mathrm{H}$ band in plane vibration. The FTIR spectrum of ChEt-ChOx/ PtNP/PPY/ITO nanobioelectrode (Figure 3(c)) also reflects the characteristic peaks of PPY/ITO electrode [34]. The ChOx and ChEt binding is indicated by the appearance of additional absorption bands at 1646 and 1560 $\mathrm{cm}^{-1}$ assigned to the carbonyl stretch (amide I band) and -N-H bending (amide II band), respectively [35]. Besides that, a broadband seen around $3457 \mathrm{~cm}^{-1}$ is attributed to amide bond present in nano bioelectrode.

Figure 4 exhibits the plot of DPV experiments, conducted in phosphate buffer $(50 \mathrm{mM}, \mathrm{pH} 7.0)$ containing 5 $\mathrm{mM}\left[\mathrm{Fe}(\mathrm{CN})_{6}\right]^{3-/ 4-}$ in the range 0.02 to $0.8 \mathrm{~V}$ (Figure 4). The value of maximum response current obtained as 4.39 $\times 10^{-5} \mathrm{~A}$ for ITO (curve a) increases to $1.88 \times 10^{-4} \mathrm{~A}$ for PPY/ITO (curve b). After addition of Pt-NP on PPY/ITO electrode, magnitude of current increases to $2.10 \times 10^{-4}$ A (curve c). Interestingly, the magnitude of peak current
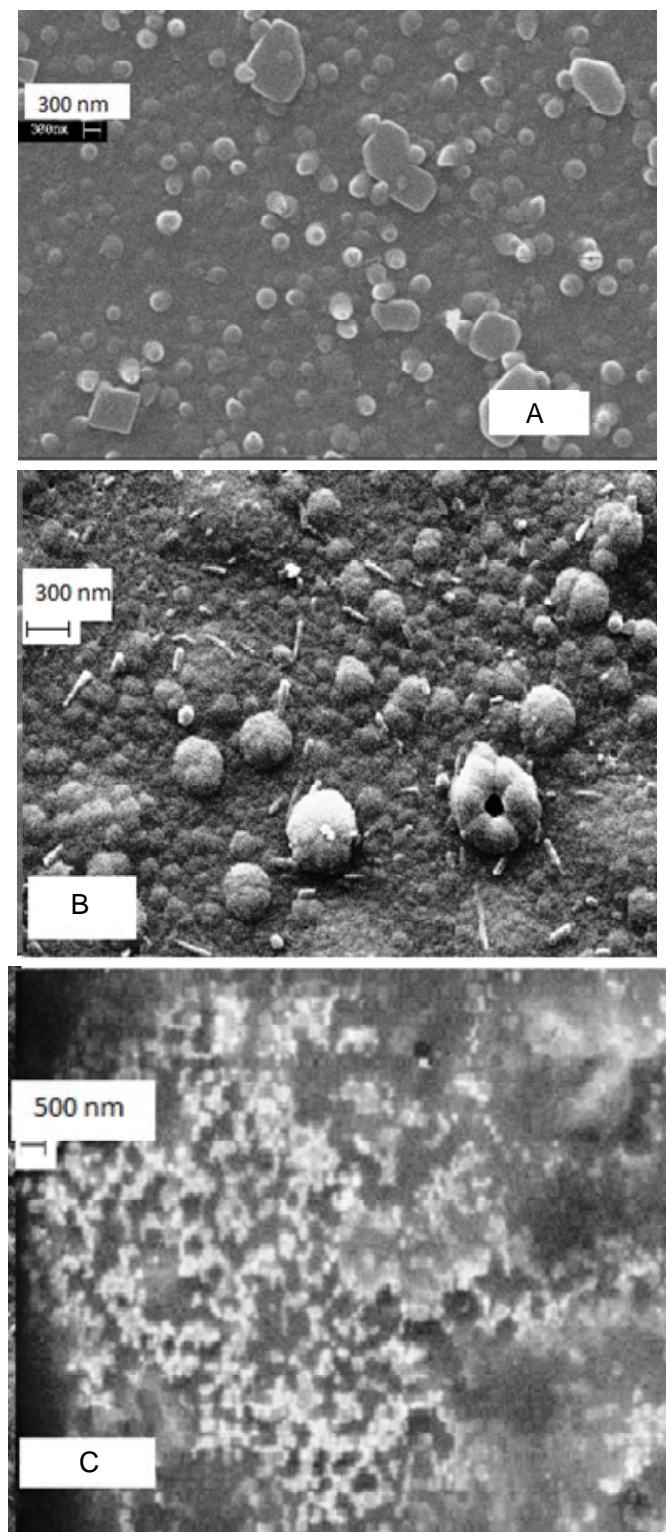

Figure 2. SEM images of the modified electrodes. A. PPY/ ITO; B. PtNP/PPY/ITO; C. ChOx-ChEt/PtNP/PPY/ITO.



Figure 3. FTIR spectra of (a) PPY/ITO, (b) PtNP/PPY/ITO and (c) ChOx-ChEt/PtNP/PPY/ITO. 


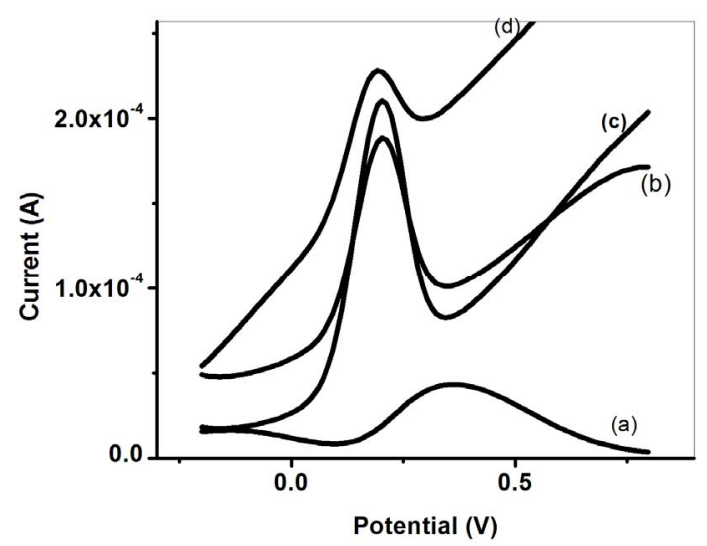

Figure 4. Differential Pulse voltammogram of (a) bare ITO, (b) PPY/ITO, (c) PtNP/PPY/ITO and (d) ChOx-ChEt/PtNP /PPY/ITO.

again increases to $2.29 \times 10^{-4} \mathrm{~A}$ to for ChOx-ChEt/ PtNP/PPY/ITO nanobioelectrode indicating PtNP/PPY/ ITO nanocomposite provides a favorable microenvironment for immobilization of enzymes wherein the immobilized enzymes have better conformation and they retain their natural activity. These results are further confirmed by cyclic voltammetric and impedimetric study. In general, bioelectrode offers less current as compared to pristine electrode due to insulating nature of the bioelectrode.

The Figure 5 shows cyclic voltammograms of (a) bare ITO (b) PPY/ITO(c) PtNP/PPY/ITO nano composite electrode and (d) ChOx-ChEt/ PtNP /PPY/ITO nano bioelectrode. The response current obtained for the PPY/ ITO electrode (curve b) is higher than that of the bare ITO electrode (curve a) and the response current of $\mathrm{PtNP} / \mathrm{PPY} / \mathrm{ITO}$ electrode $\left(5.12 \times 10^{-4} \mathrm{~A}\right)$ is 1.5 times higher than that of PPY/ITO electrode $\left(3.32 \times 10^{-4} \mathrm{~A}\right)$. This clearly indicates that PtNP have increased electroactive surface area of PPY/ITO electrode and the use of PtNP/PPY/ITO electrode leads to accelerated electron transfer between medium and electrode. Moreover, the peak response current further increases after immobilization of ChOx-ChEt onto PtNP/PPY/ITO electrode (Figure 5(d)) revealing that PtNP provides a favorable conformational environment for ChOx-ChEt loading resulting in improved electron transport between $\mathrm{ChOx}-\mathrm{ChEt}$ and electrode. The results are also supported by the DPV results as shown in Figure 4.

Figures 6A and $\mathbf{B}$ show the CV of PtNP/PPY/ITO electrode and ChOx-ChEt/PtNP/PPY/ITO bioelectrode as a function of scan rate $(20-160 \mathrm{mV} / \mathrm{s})$. The relationships between the peak current and corresponding potential with scan rate are shown in Table 1. It can be seen that the magnitudes of cathodic peak and anodic peak current increase with increasing scan rate (Figures 6A(a) and $\mathbf{B}(\mathbf{a}))$. This linear dependence can be expressed by

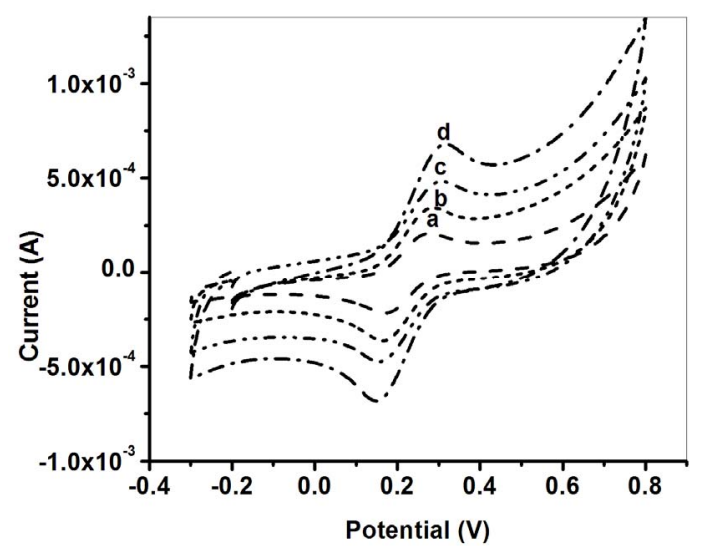

Figure 5. Cyclic voltammogram of (a) bare ITO, (b) PPY/ ITO, (c) PtNP/PPY/ITO nano electrode and (d) ChOxChEt/ PtNP/PPY/ITO nano bioelectrode.

the Equations (1) to (4) in Table 1. Both the anodic and cathodic peak current exhibit a linear relationship with the scan rate, suggesting that electro-chemical reaction is a diffusion-controlled process for both nano composite and nano bioelectrode. The peak potential also increases linearly with $\log$ of scan rate (Figures $6 \mathbf{A}(\mathbf{b})$ and $\mathbf{B}(\mathbf{b})$ ) indicating a diffusion controlled process. The values of slope obtained from the plots of the peak current against the scan rate for ChOx-ChEt/PtNP/PPY/ITO nanobioelectrode are higher than the slope of the PtNP/PPY/ITO electrode indicating a favorable microenvironment for enzymes with nanobioelectrode. Table 1 (Equations (1)(8)) shows linear equations, slope, Regression Coefficient, and Standard deviation for the electrochemistry of the electrodes. The characteristics features of the nanobioelectrode as shown in Table 1 reflect that good electron transport is retained in the $\mathrm{ChOx}-\mathrm{ChEt} / \mathrm{PtNP} / \mathrm{PPY} /$ ITO nano bioelectrode.

\subsection{Electrochemical Impedance Spectroscopic Studies of PtNP/PPY/ITO Electrode and ChOx-ChEt/PtNP/PPY/ITO}

During the last decade, Electrochemcial Impedance Spectroscopy (EIS) has been widely used for probing various types of biomolecular interactions based immunosensors, DNA hybridization, rapid biomolecular screening, cell culture monitoring and relevant literature has been comprehensively reviewed [31,36-38]. EIS is a measure of the response of an electrochemical cell subjected to a small amplitude sinusoidal voltage signal as a function of frequency $[39,40]$. The resulting sinusoidal current expressed with respect to the perturbing (voltage) wave, and the ratio $V(t) / I(t)$ is defined as the impedance $(Z)$. Impedance is expressed as a complex number, where the real component measures the ohmic resistances and the imaginary one is the capacitive reactance. The Nyquist and Bode plots are the most popular formats 
Table 1. Characteristics of PtNP/PPY/ITO nanocomposite electrode and ChOx-ChEt/PtNP/PPY/ITO nanobioelectrode.

\begin{tabular}{|c|c|c|c|c|c|}
\hline Electrode & Slope & Regression Coefficient & Standard Deviation & Linear Equation & \\
\hline \multirow{4}{*}{ PtNP/PPY/ITO } & 9.3 & 0.99 & $6.22 \mathrm{E}-05$ & $I_{p}=244+9.32 \times$ scan rate & (1) \\
\hline & -8.6 & 0.98 & $1.03 \mathrm{E}-04$ & $I_{C}=-259-8.6 \times$ scan rate $\mathrm{I}$ & (2) \\
\hline & 0.1 & 0.98 & 0.004 & $E_{p}=0.14+0.1 \times \log \mid($ scan rate $) \mid$ & (3) \\
\hline & -0.09 & 0.98 & 0.004 & $E_{C}=0.298-0.09 \times \log ($ scan rate $)$ & (4) \\
\hline \multirow{4}{*}{ ChOx-ChEt/PtNP/PPY/ITO } & 11 & 0.98 & $9.8 \mathrm{E}-05$ & $I_{p}(\mathrm{~A})=248 \mu \mathrm{A}+11 \mu \mathrm{A} \times$ scan rate & $(5)$ \\
\hline & -9.02 & 0.97 & $1.08 \mathrm{E}-04$ & $I_{C}=-367-9.02 \times$ scan rate & (6) \\
\hline & 0.1 & 0.98 & 0.004 & $E_{p}=0.14+0.1 \times \log ($ scan rate $)$ & (7) \\
\hline & -0.1 & 0.98 & 0.005 & $E_{C}=0.310-0.1 \times \log ($ scan rate $)$ & $(8)$ \\
\hline
\end{tabular}

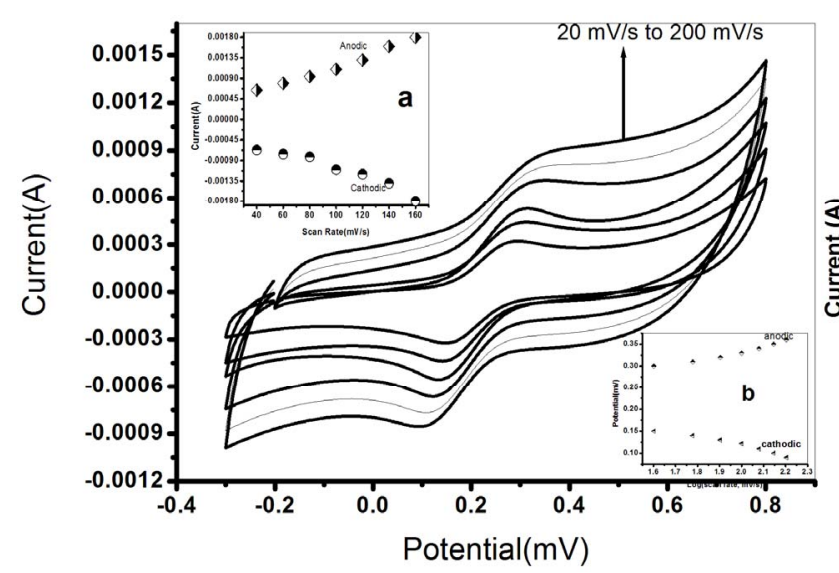

A

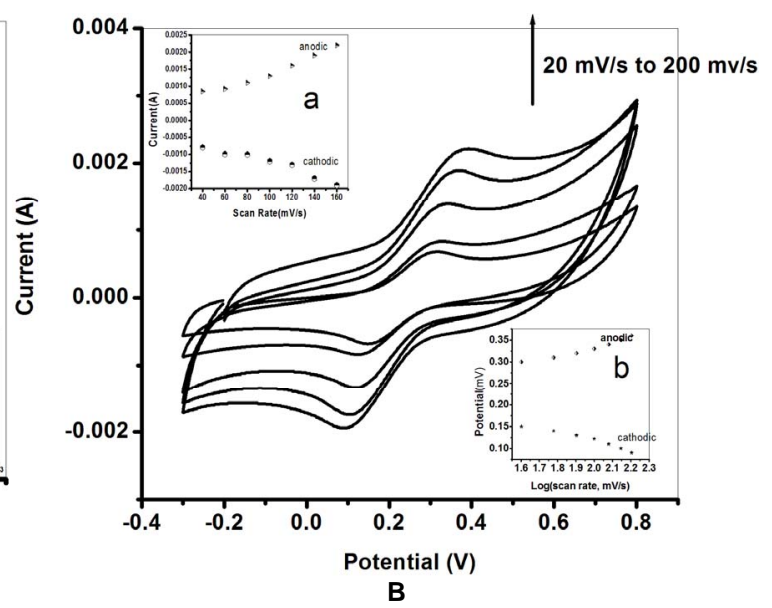

B

Figure 6. A. Cyclic voltammograms of (a) PtNP/PPY/ITO nano electrode as a function of scan rate (20 to $200 \mathrm{mV} / \mathrm{s})$. Inset: (a) plot of variation of peak current (anodic and cathodic) and scan rate and (b) variation of potential and log of scan rate. $B$. Cyclic voltammograms of ChOx-ChEt/ PtNP/PPY/ITO nano bioelectrode as a function of scan rate (20 to $160 \mathrm{mV} / \mathrm{s})$. Inset: (a) plot of variation of current and scan rate and (b) variation of potential and log of scan rate.

for evaluating electrochemical impedance data. In the Nyquist format, the imaginary impedance component $\left(Z^{\prime}\right.$ out-of-phase) is plotted against the real impedance component ( $Z^{\prime \prime}$ in-phase) at each excitation frequency, whereas in the latter format, both the logarithm of the absolute impedance, $|Z|$ and the phase shift, are plotted against the logarithm of the excitation frequency $[40]^{2}$.

The complex impedance can be presented as the sum of the real $\left(Z^{\prime}\right)$ and imaginary $\left(Z^{\prime \prime}\right)$ components that mainly originate from the resistance and capacitance of the cell and can be calculated using Equation (9) (for parallel circuit).

$$
Z=Z^{\prime}+j Z=R_{s}+\frac{R_{p}}{\left(1+w^{2} C^{2} R_{p}^{2}\right)}+\frac{C_{d l} R_{p}^{2}}{\left(1+w^{2} C^{2} R_{p}^{2}\right)}
$$

where, $R_{s}=$ Ohmic resistance of the electrolyte solution; ${ }^{2}$ http://www.ceacsu.edu.pk/PDF\%20file/Journal\%20Vol\%208\%20No $\% 201 \% 20$ and\%202/69-71-PJAEC-P.pdf.
$R_{p}=$ Polarization resistance $\left[R_{p}\right.$ at 0 potential describes as electron charge transfer resistance $\left.\left(R_{C T}\right)\right], w=$ Radial frequency and $C_{d l}=$ Double layer capacitance.

$C_{d l}$ calculated by following Equation (10).

$$
C_{d l}=\pi f_{\max } R_{C T}
$$

$C_{d l}$ and $R_{C T}$, depend on the dielectric and insulating features at the electrode/electrolyte interface. The semicircle diameter of EIS spectra gives value of $R_{C T}$ that reveals charge-transfer resistance of redox probe at the electrode interface. However, $R_{s}$ represents bulk properties of the electrolyte solution and diffusion of applied redox probe are not affected by biochemical reaction occurring at the electrode interface ${ }^{3}$. The Equations (9) and (10) represent relationship between the total impedance and other electrochemical parameters such as $R_{C T}$ and $C_{d l}$. The interfacial properties of the electrode in the ${ }^{3} \mathrm{http} / / /$ www.researchgate.net/publication/248517893_Sol-gel_derived_ nanostructured_zirconia_for_cholesterol_detection. 
electrolyte depend on charge transfer resistance $\left(R_{C T}\right)$ and capacitance $\left(C_{d l}\right)$.

The Figure 7 shows the impedance spectra of (a) bare ITO (b) PPY/ITO (c) PtNP/PPY/ITO and (d) ChOx$\mathrm{ChEt} / \mathrm{PtNP} / \mathrm{PPY} / \mathrm{ITO}$. It has been observed that charge transfer resistance $\left(R_{C T}\right)$ value for PPY/ITO electrode (821.3 $\Omega$, Figure 7, curve b) at $0 \mathrm{~V}$ bias potential is smaller than that of the bare ITO electrode $(1044.8 \Omega)$. Similarly, the value of charge transfer resistance (586.8 $\Omega, R_{C T}$ ) of PtNP/PPY/ITO electrode is lower (Figure 7, curve c) than PPY/ITO electrode, revealing that PtNP increases the electroactive surface area of electrode resulting in easier electron transfer from the medium to electrode due to increased diffusion of redox species $[\mathrm{Fe}(\mathrm{III}) / \mathrm{Fe}(\mathrm{IV})]$ onto surface charged nanocomposite PtNP/PPY/ITO film. Interestingly, $R_{C T}$ value further decreases to $353.92 \Omega$ (Figure 7, curve d) after the immobilization of ChOx-ChEt onto PtNP/PPY/ITO revealing that PtNP provides a desirable microenvironment for the immobilization of ChOx-ChEt [41]. It can be assumed that $\mathrm{ChOx}$-ChEt rearrange their structure and presents better conformation onto PtNP/PPY/ITO electrode. Thus ChOx-ChEt/PtNP/PPY/ITO nano bioelectrode provides easier electron transfer due to increased active sites for electrical contact between electrode and the redox label in solution. In practice, an ideal semicircle characteristics is generally not observed in impedance spectra. It is normally an inclined semicircle with its centre depressed below the real axis by a finite angle referred to as the depression angle. The depression angle $(\boldsymbol{\theta})$ by which such a semicircular is displaced below the real axes, is related to the width of the relaxation time distribution and is an important parameter. It can be seen that arc of the semicircle with least $q$ value, that is less distorted from centre of the real axis can be calculated using Equation (11).

$$
\text { Depression angle } \theta=\left(\frac{(1-n) \pi}{2}\right)
$$

where, $n$ is the fractional exponent and calculated form the standard commercial software available with the instrument. From the above discussion, it is clear that it is necessary to find out the optimum condition at which the minimum depression angle is obtained for both type of electrodes and the cholesterol nano biosensor should be evaluated at that optimum condition. The EIS spectra of PtNP/PPY/ITO electrode and ChEt-ChOx/PtNP/PPY/ ITO bioelectrodes are studied as a function of potential $(0-0.20 \mathrm{~V})$ to locate an ideal condition.

The Figures $8 \mathbf{A}$ and $\mathbf{B}$, shows the EIS spectra of PtNP/PPY/ITO electrode and ChOx-ChEt/PtNP/PPY/ ITO bioelectrode, respectively as a function of potential $(0.0$ to $0.2 \mathrm{~V})$. The $\mathrm{R}_{\mathrm{CT}}$ values both for the PtNP/PPY/ ITO electrode and ChOx-ChEt/PtNP/PPY/ITO nano bio-

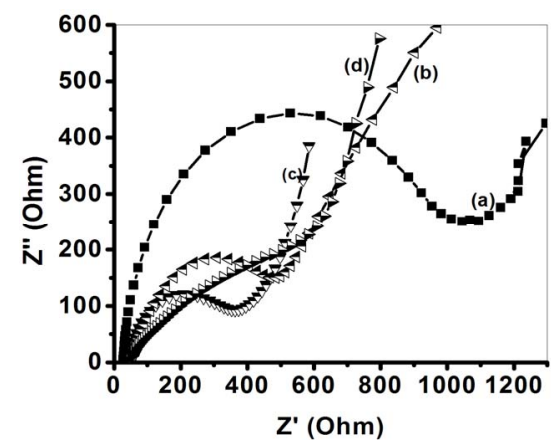

Figure 7. Electrochemical impedience spectra of (a) bare ITO, (b) PPY/ITO, (c) PtNP/PPY/ITO and (d) ChOx-ChEt/ PtNP/PPY/ITO.

electrode have been found to decrease linearly with increase in bias potential (Figures 8A(b) and $\mathbf{B}(\mathbf{b})$ ) and they follow Equations (12) and (13).

$$
\begin{gathered}
R_{C T}[\mathrm{PtNP} / \mathrm{PPY} / \mathrm{ITO}]=622-2372 \times E \\
\text { with regression coefficient of } 0.99 . \\
R_{C T}[\mathrm{ChOx}-\mathrm{ChEt} / \mathrm{PtNP} / \mathrm{PPY} / \mathrm{ITO}]=349-1354 \times E \\
\text { with regression coefficient of } 0.99 .
\end{gathered}
$$

This reveals facile electron transfer kinetics wherein resistance controls the electron transfer kinetics of the redox probe at the electrode. This electron transfer resistance $\left(R_{C T}\right)$ can be translated into exchange current under the equilibrium $\left(I_{0}\right)$ and then heterogeneous electrontransfer rate constant $\left(k_{C T}\right)$ according to the Equation (14) [30]. The value of $k_{C T}$ for $\mathrm{ChOx}-\mathrm{ChEt} / \mathrm{PtNP} / \mathrm{PPY} / \mathrm{ITO}$ bioelectrode is higher $\left(7.6 \times 10^{-5} \mathrm{~cm} / \mathrm{s}\right)$ than that of the $\mathrm{PtNP} / \mathrm{PPY} / \mathrm{ITO}$ electrode $\left(4.3 \times 10^{-5} \mathrm{~cm} / \mathrm{s}\right)$.

$$
R_{C T}=\frac{R T}{n F I_{0}}, I_{0}=n F A k_{C T}[S], k_{C T}=\frac{R T}{n^{2} F^{2} A R_{C T}[S]}
$$

where, $R=$ Gas constant, $T=$ Absolute temperature $(\mathrm{K})$, $F=$ Faraday constant, $A=$ Electrode area $\left(\mathrm{cm}^{2}\right), S=$ Bulk concentration of redox probe $\left(\mathrm{mol} \cdot \mathrm{cm}^{3}\right)$ and $n=$ Number of transferred electrons per molecule of the redox probe.

Figure 9 shows the variation of depression angle $(\theta)$ obtained for PtNP/PPY/ITO electrode and ChOx-ChEt/ PtNP/PPY/ITO bioelectrode as a function of applied potential. It is observed that values of depression angle $(\theta)$ for PtNP/PPY/ITO electrode and ChOx-ChEt/PtNP/PPY/ ITO bioelectrode decrease on increasing the potential from 0 to $0.2 \mathrm{~V}$. However, $0.06 \mathrm{~V}$ is the minimum potential at which the values of $(\theta)$ obtained for PtNP/PPY/ ITO electrode $\left(0.4^{\circ}\right)$ and $\mathrm{ChOx}-\mathrm{ChEt} / \mathrm{PtNP} / \mathrm{PPY} / \mathrm{ITO}$ bioelectrode $\left(0.3^{\circ}\right)$ are close to the values of depression angle $(\theta)$ at higher potential $(0.2 \mathrm{~V})$. This suggests that $0.06 \mathrm{~V}$ can be chosen as the working potential for electro-chemical sensing wherein the semicircle of the experimental data is near the centre of real axes with com- 


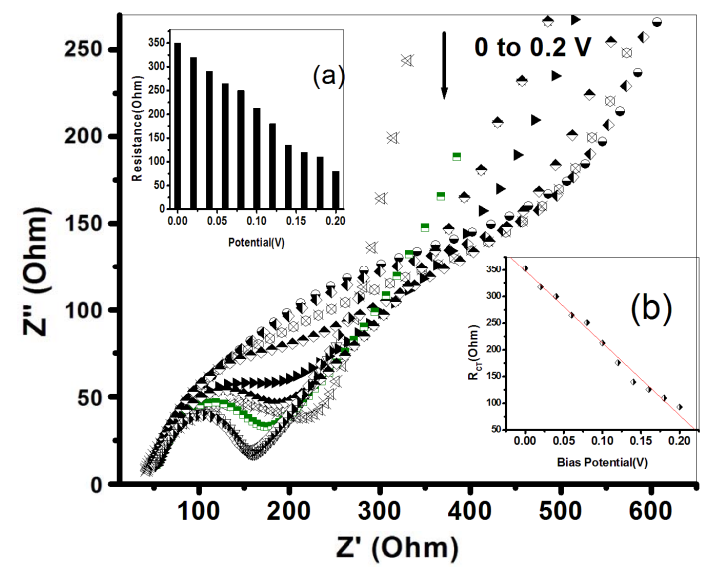

A

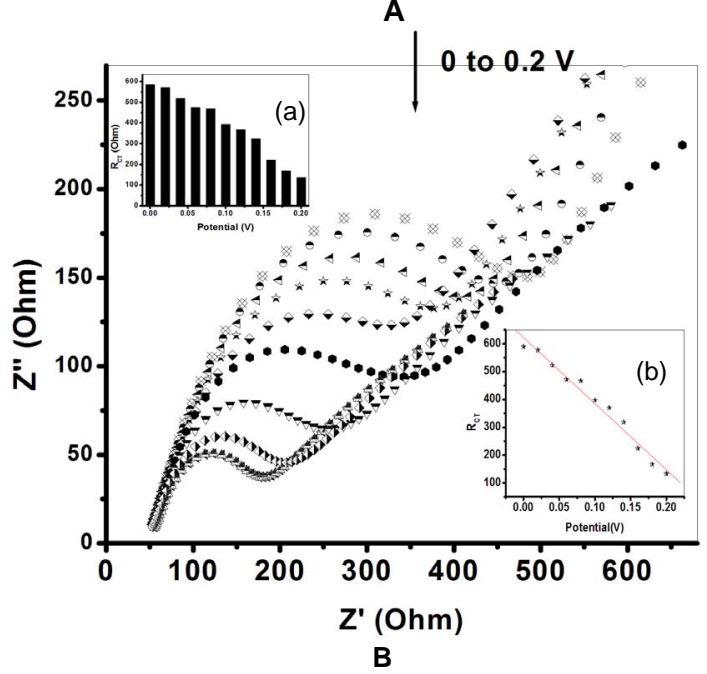

Figure 8. A. Electrochemical Impedance spectra [EIS] of PtNP/PPY/ITO nano-electrode as function of potential $(0$ 0.2 v). Inserts: (a) Plot of charge transfer resistance $\left(R_{C T}\right)$ and applied potential; (b) Linear relationship between $R_{C T}$ and potential. $B$. Electrochemical Impedance spectra [EIS] of Chox-ChEt/PtNP/PPY/ITO nano bioelectrode as function of potential $(0-0.2 \mathrm{v})$. Inserts: (a) Plot of charge transfer resistance $\left(R_{C T}\right)$ and potential; (b) Linear relationship between $R_{C T}$ and Potential.

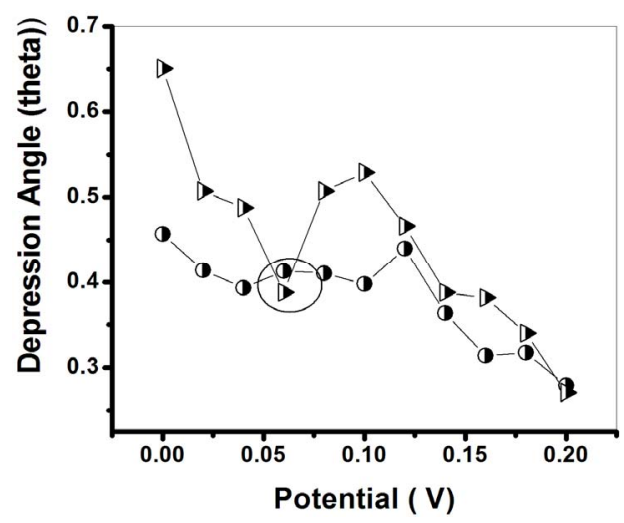

Figure 9. Plot between depression angle and applied potential for PtNP-PPY/ITO and ChOx-ChEt/PtNP-PPY/ITO electrode. plex planes.

It is necessary to mention here that impedance behavior of an electrode depends on the circuit, it follows. In order to find out the best fitted circuit, impedance spectra of PtNP/PPY/ITO has been compared with computer simulated spectra using six different electronic circuits (EC) based on Randles and Ershler theoretical model. Figure 10 shows that the Faradic impedance spectra of PtNP/PPY/ITO electrode, fitted with computer simulated spectra using six different electronic circuits (EC). The best fit between the simulated electronic circuit and experimental spectra is obtained for electronic circuit $\mathrm{EC}_{4}$ i.e., $\mathrm{EC}_{4}[\mathrm{R}(\mathrm{Q}[\mathrm{R}(\mathrm{Q}[\mathrm{RT}])])]$. And the minimum error has been observed in EC4 as compared to other circuits.

Figure 11 shows EIS spectra simulated by $\mathrm{EC}_{4}$ $[\mathrm{R}(\mathrm{Q}[\mathrm{R}(\mathrm{Q}[\mathrm{RT}])])]$ for PtNP/PPY/ITO electrode and ChOx-ChEt/PtNP/PPY/ITO nano bioelectrode at potential $0.06 \mathrm{~V}$. It can be seen that $R_{C T}$ value of for ChOx$\mathrm{ChEt} / \mathrm{PtNP} / \mathrm{PPY} / \mathrm{ITO}$ bioelectrode $(264.98 \Omega)$ is lower than that of the PtNP/PPY/ITO electrode (475.04 $\Omega$ ) revealing that PtNP provides a desired micro-environment for immobilization of $\mathrm{ChOx}-\mathrm{ChEt}$ where in the immobilized enzyme has better conformation and it retains its natural activity. But the values of double layer capacitance, $C_{d l}$ are almost identical for the electrodes (Table 2).

Figure 12 shows the enzyme activities of the $\mathrm{ChOx}$ $\mathrm{ChEt} / \mathrm{PtNP} / \mathrm{PPY} / \mathrm{ITO}$ nano bioelectrodes, evaluated as a function of $\mathrm{pH}$ varying from 6.0 to 7.8 at room temperature $\left(25^{\circ} \mathrm{C}\right)$ with $100 \mathrm{mg} / \mathrm{dl}$ cholesterol oleate solution. The least value of $R_{C T}$ obtained at $\mathrm{pH} 7.0$ (Figure 12) indicates that $\mathrm{ChOx}-\mathrm{ChEt} / \mathrm{PtNP} / \mathrm{PPY} / \mathrm{ITO}$ bioelectrodes are more active at $\mathrm{pH} 7.0$ at which $\mathrm{ChOx}$ and ChEt molecules retain the natural structure and do not get denatured. Thus all the experiments have been conducted at $\mathrm{pH} 7.0$ at $25^{\circ} \mathrm{C}$.

Figures 13A and $\mathbf{B}$ represents the response studies of the $\mathrm{ChOx}-\mathrm{ChEt} / \mathrm{PtNP} / \mathrm{PPY} / \mathrm{ITO}$ nano bioelectrode which have been investigated as a function of cholesterol oleate concentration $\left(100 \mu \mathrm{L}\right.$ of $2.5 \times 10^{-4}$ to $\left.6.5 \times 10^{-3} \mathrm{M} / \mathrm{l}\right)$ at the bias potential of $0.06 \mathrm{~V}$ and $\mathrm{pH}$ 7.0. The observed experimental data of $\mathrm{ChOx}-\mathrm{ChEt} / \mathrm{PtNP} / \mathrm{PPY} / \mathrm{ITO}$ nanobioelectrode as a function of cholesterol oleate concentration data is fitted using $\mathrm{EC}_{4}[\mathrm{R}(\mathrm{Q}[\mathrm{R}(\mathrm{Q}[\mathrm{RT}])])]$. The

Table 2. The parameters of electrochemical impedance spectra [EIS] for (a) PtNP/PPY/ITO and (b) ChOx-ChEt/ PtNP/PPY/ITO electrodes at $0.06 \mathrm{~V}$.

\begin{tabular}{ccccc}
\hline $\begin{array}{c}\text { Curve } \\
\text { (Figure 10) }\end{array}$ & Electrode & $\begin{array}{c}\text { Rs- } \\
\text { value }\end{array}$ & Cdl-value & $\begin{array}{c}\text { RCT- } \\
\text { value }\end{array}$ \\
\hline a & PtNP/PPY/ITO & 48.18 & $6.3665 \mathrm{E}-06$ & 475.04 \\
b & ChOx-ChEt/PtNP/PPY/ITO & 41.44 & $5.9794 \mathrm{E}-06$ & 264.98 \\
\hline
\end{tabular}




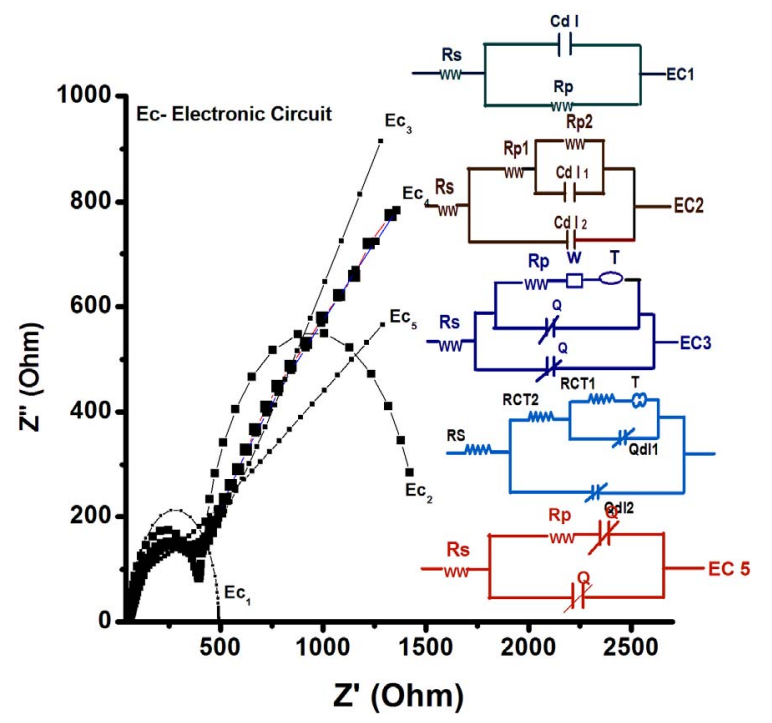

Figure 10. Electrochemical impedance spectra of PtNP/ PPY/ITO electrode fitted using different electronic circuits.

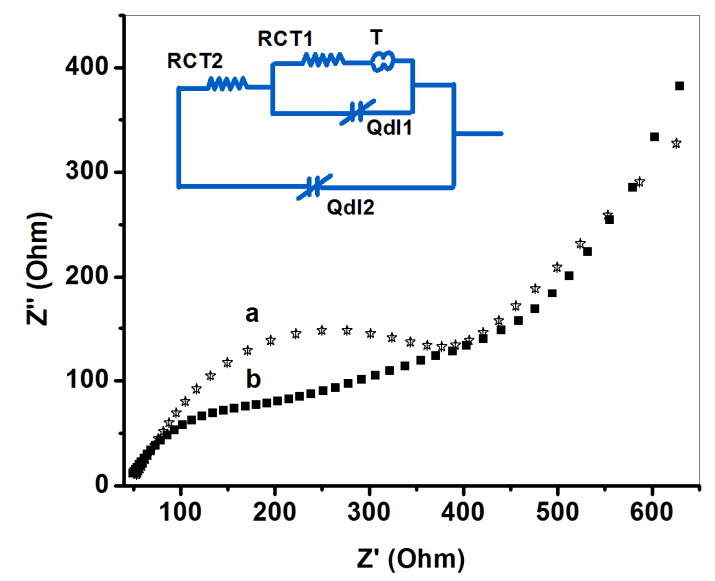

Figure 11. Electrochemical Impedance spectra of (a) PtNP/ PPY/ITO and (b) ChOx-ChEt/PtNP/PPY/ITO at $0.06 \mathrm{v}$.

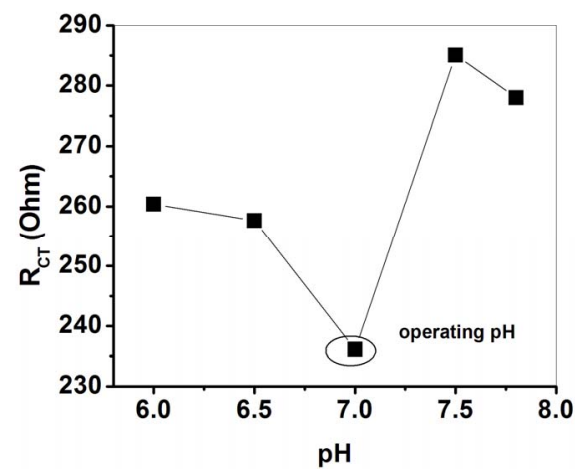

Figure 12. Electrochemical impedience spectra of ChOxChEt/PtNP/PPY/ITO nano-bioelectrode for $\mathrm{pH}$ studies.

surface charge transfer resistance $\left(R_{C T}\right)$ decreases with increase in cholesterol oleate concentration as shown in Figure 13A(a). At the same time double layer capaci- tance $\left(C_{d l}\right)$ of nanobioelectrodes increases with increasing the concentration of cholesterol oleate as shown in Figure $13 \mathbf{A}(\mathbf{b})$. This can be attributed to the fact that ChOx and ChEt present on ChOx-ChEt/PtNP/PPY/ITO nanobioelectrodes convert cholesterol oleate to choleste4-ene-3-one. The generated electrons during the reoxidation of $\mathrm{ChOx}$ after enzymatic reaction are transferred to the ChEt-ChOx/PtNP/PANI/ITO electrode via $\mathrm{Fe}(\mathrm{III}) /$ $\mathrm{Fe}(\mathrm{IV})$ couples that helps in enhanced charge transfer rate leading to decreased in $R_{c t}$ value resulting in increased sensitivity of the sensor. The biochemical reaction mechanism at ChOx-ChEt/PtNP/PPY/ITO bioelectrode is shown in Scheme 2. The overall biochemical reaction mechanism demonstrates the decrease in charge transfer resistance of the nano bioelectrode with increase in cholesterol oleate concentration as the ionic conduc-

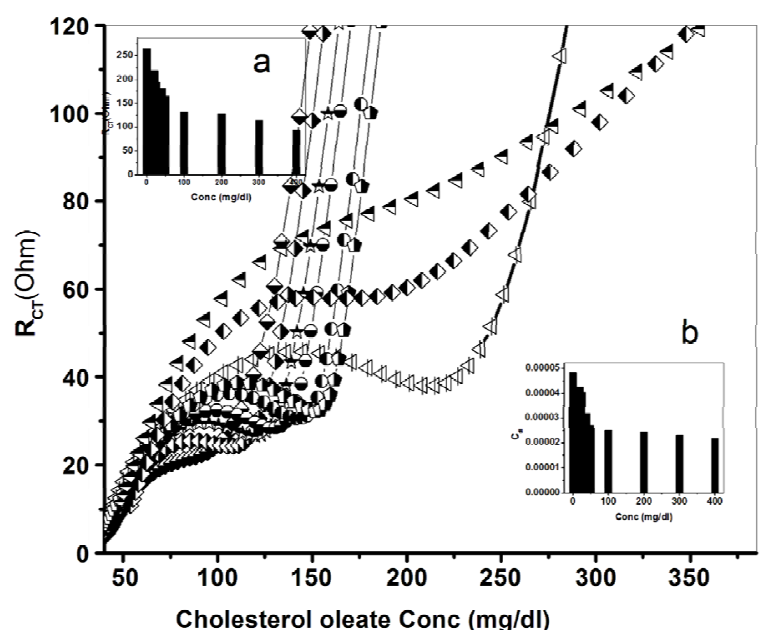

A



Figure 13. A. Electrochemical Impedance spectra [EIS] response of $\mathrm{ChOx}-\mathrm{ChEt} / \mathrm{PtNP} / \mathrm{PPY} / \mathrm{ITO}$ bioelectrode as a function of cholesterol oleate concentration $(0.3-6.1 \mathrm{mM})$ at bias potential of $0.06 \mathrm{~V}$ and fit using EC4.13; B. Calibration curve between $R_{C T}$ value and logarithm of cholesterol oleate concentration $(0.3-6.1 \mathrm{mM})$. 
tivity of the electrode increases. The Equation (15) represents the linear regression for ChOx-ChEt/PtNP/PPY/ ITO bioelectrode as obtained from the calibration curve by plotting $R_{C T}$ vs log of cholesterol oleate concentration.

$$
R_{C T}=195-196 \times \log [\text { cholesterol concentration] }
$$

with a correlation coefficient of 0.99 .

The results of experiments carried out in triplicate sets reveal reproducibility of the system within $5 \%$. It has been shown that the ChOx-ChEt/PtNP/PPY/ITO bioelectrodes represents characteristics such as low detection limit $(0.25 \mathrm{mM})$, fast response time $(20 \mathrm{~s})$, high sensitivity $\left(196 \Omega / \mathrm{mM} / \mathrm{cm}^{2}\right)$. The detection limit is determined by the minimum concentration of cholesterol oleate at which decrease in $R_{C T}$ value as compared to bioelectrode is observed. As impedance measurement is carried out at $0.06 \mathrm{~V}$, the developed nano bioelectrode shows excellent reusability (data not shown). The shelf-life of the ChOx$\mathrm{ChEt} / \mathrm{PtNP} / \mathrm{PPY} / \mathrm{ITO}$ nanobioelectrode measured after an interval of 1 week has been estimated as 7 weeks. The decrease in the value of $R_{C T}$ has been found to be about $10 \%$ up to about 7 weeks after which the current decreases sharply resulting in about $70 \%$ loss in about 10 weeks (data not shown). The value of the MichaelisMenten constant $(\mathrm{Km})$ obtained as $0.2 \mathrm{mM}$ for ChOx$\mathrm{ChEt} / \mathrm{PtNP} / \mathrm{PPY} / \mathrm{ITO}$ using Lineweaver-Burke plot reveals that PtNP/PPY/ITO matrix facilitates enzymatic reaction and helps the immobilized enzyme to achieve better conformation for faster enzymatic reaction resulting in enhanced enzymatic activity. The conformational changes are known to affect a biochemical reaction at bioelectrode that in turn may be influenced by the surface morphology and the nature of immobilization matrix. The double layer capacitance $\left(C_{d l}\right)$ generally increases with the increase of charge transfer resistance $\left(R_{C T}\right)$. The same trend is observed with the $C_{d l}$ value of the nanobioelectrode with the concentration of cholesterol oleate (Figure 13A(a) and (b)).

Figure 14 shows the selectivity of ChOx-ChEt/PtNP/ PPY/ITO nanobioelectrode, estimated by comparing magnitude of $R_{C T}$ by adding normal concentration of interferents such as glucose $(5 \mathrm{mM})$, ascorbic acid $(0.05$ $\mathrm{mM})$, uric acid $(0.1 \mathrm{mM})$, urea $(5 \mathrm{mM})$, sodium pyruvate acid $(0.5 \mathrm{mM})$ and sodium ascorbate $(0.05 \mathrm{mM})$. The role of interferents has been examined by mixing equal volume of desired interferent with cholesterol. In Figure 14, the first bar (Cho-oleate) shows the value of charge transfer resistance $\left(R_{C T}\right)$ obtained with $3.6 \mathrm{mM}$ cholesterol oleate. The remaining bars show the variation of the $R_{C T}$ corresponding to the mixture of cholesterol oleate and interferents in a 1:1 ratio. The straight line parallel to the $\mathrm{X}$-axis shows the observed $R_{C T}$ in the presence of desired interferents, revealing a maximum of $7.4 \%$ interference. The percentage interference $(\%$ inter) has been

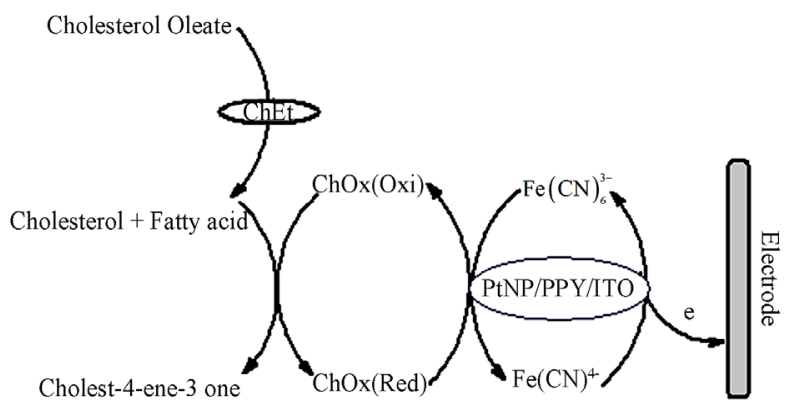

Scheme 2. Schematic diagram for biochemical reaction at ChOx-ChEt/PtNP/PPY/ITO bioelectrode for total cholesterol detection.

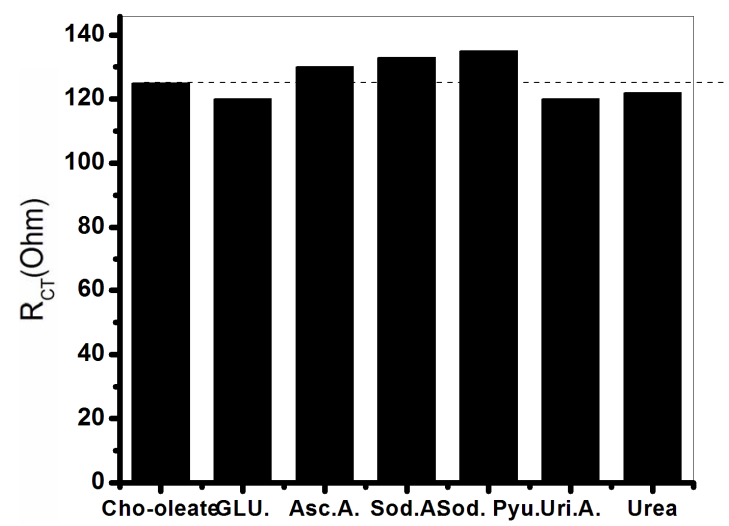

Figure 14. Electrochemical impedience spectral of ChOxChEt/PtNP/PPY/ITO nano-bioelectrode for interferent studies.

calculated using Equation (16) for various interferents:

$$
\% \text { Interference }=\frac{\left[R_{C T_{c h o}}-R_{C T_{I n t}}\right]}{R_{C T_{c h o}}} \times 100
$$

where, $R_{C T_{c h o}}$ is the charge transfer resistance of the nanobioelectrode obtained with $3.6 \mathrm{mM}$ cholesterol oleate concentration and $R_{C T_{I n t}}$ is the charge transfer resistance corresponding to the mixture of cholesterol oleate and interferents in a 1:1 ratio. It has been found that $\mathrm{ChOx}-\mathrm{ChEt} / \mathrm{PtNP} / \mathrm{PPY} / \mathrm{ITO}$ nano bioelectrode is not significantly affected by the presence of interferents The biosensing characteristics of ChEt-ChOx/PtNP/PPY/ITO bioelectrode has been compared with other total cholesterol biosenosrs, reported in literature have been summarized in Table 3. It can be noted that the Km value obtained by the impedance measurement reflects actual interaction between enzyme and the substrate as the impedance spectra depends on interfacial property.

\section{Conclusion}

The matrices of Pt-nanoparticle (PtNP) and PPY multilayer electrodes have been fabricated for the development of total cholesterol biosensor. The novelty of 
Table 3. Shows characteristics of the ChEt-ChOx/PPYMWCNT/PTS/ITO bio-electrode including reported in the literature.

\begin{tabular}{|c|c|c|c|}
\hline Sl No & Components of biosensor & Characteristics & Reference \\
\hline 1) & $\begin{array}{c}\text { [Mat]: Ppy } \\
\text { [E]: ChOx, ChEt } \\
\text { [Mol]: Adsorption } \\
{[\mathrm{M}]: \text { Ampero. vs Ag/AgCl }}\end{array}$ & $\begin{array}{l}{[\mathrm{L}]: 1-8 \mathrm{mM} / 1} \\
{[\mathrm{SL}]: 4 \text { weeks }}\end{array}$ & $\begin{array}{c}\text { Singh et al. } \\
\text { [21] }\end{array}$ \\
\hline 2) & $\begin{array}{c}\text { [Mat]: Polyaniline } \\
\text { [E]: ChEt, ChOx } \\
{[\mathrm{Mol}]: \text { Covalent }} \\
{[\mathrm{M}]: \text { Ampero. vs } \mathrm{Ag} / \mathrm{AgCl}}\end{array}$ & $\begin{array}{c}{[\mathrm{L}]: 50-500 \mathrm{mg} / \mathrm{dl}} \\
{[\mathrm{RT}]: 40 \mathrm{~s}} \\
{[\mathrm{SL}]: 6 \text { weeks }} \\
{[\mathrm{S}]: 7.4 \times 10^{-4} \mathrm{nA}}\end{array}$ & $\begin{array}{l}\text { Singh et al. } \\
\text { [22] }\end{array}$ \\
\hline 3) & $\begin{array}{c}\text { [Mat]: Polyaniline } \\
\text { [E]: ChE, ChOx, HRP } \\
\text { [Mol]: Covalent } \\
\text { [M]: Ampero. vs Ag/AgCl }\end{array}$ & 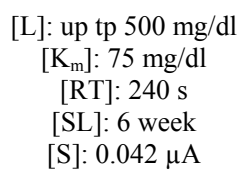 & $\begin{array}{l}\text { Singh et al. } \\
{[23]}\end{array}$ \\
\hline 4) & $\begin{array}{c}\text { [Mat]: Dithiobissuccinimidyl } \\
\text { propionate } \\
\text { [E]: ChOx, ChEt } \\
\text { [Mol]: Covalent } \\
\text { [M]: Ampero. vs Ag/AgCl }\end{array}$ & $\begin{array}{c}{[\mathrm{L}]: 50-400 \mathrm{mg} / \mathrm{dl}} \\
{\left[\mathrm{K}_{\mathrm{m}}\right]: 0.95 \mathrm{mM}} \\
{[\mathrm{Sl}]: 7 \text { weeks }}\end{array}$ & $\begin{array}{c}\text { Arya et al. } \\
\quad[40]\end{array}$ \\
\hline 5) & $\begin{array}{c}\text { [Mat]: 3-aminopropyl-modified } \\
\text { controlled-pore glass (APCPG) } \\
\text { [E]: ChOx, ChEt, HRP } \\
\text { [Mol]: Covalent } \\
\text { [M]: Ampero. vs Ag/AgCl }\end{array}$ & $\begin{array}{c}{[\mathrm{L}]: 1.2 \mu 1-1 \mathrm{mM} / 1} \\
{\left[\mathrm{~K}_{\mathrm{m}}\right]: 2 \mathrm{mM}} \\
{[\mathrm{RT}]: 120 \mathrm{~s}} \\
{[\mathrm{SL}]: 3 \text { weeks }}\end{array}$ & $\begin{array}{l}\text { Arya et al. } \\
\text { [42] }\end{array}$ \\
\hline 6) & $\begin{array}{c}\text { [Mat]: AT cut quartz crystal } \\
\text { [E]: ChOx, ChEt } \\
\text { [M]: Impedence }\end{array}$ & - & $\begin{array}{c}\text { Arya et al. } \\
\text { [43] }\end{array}$ \\
\hline 7) & $\begin{array}{c}\text { [Mat]: } \\
\text { CHIT-SiO }- \text { MWCNT/ITO } \\
\text { [E]: ChET, CHOx } \\
\text { [Mol]: Covalent } \\
\text { [M]: Ampero. (DPV) vs } \\
\text { Ag/AgCl }\end{array}$ & $\begin{array}{c}{[\mathrm{L}]: 0.15-7.68 \mathrm{mM}} \\
{\left[\mathrm{K}_{\mathrm{m}}\right]: 0.52 \mathrm{mM}}\end{array}$ & $\begin{array}{c}\text { Pratima et } \\
\text { al. [25] }\end{array}$ \\
\hline 8) & $\begin{array}{c}\text { [Mat]: Polypyrrole/MWCNT } \\
\text { nano composite } \\
\text { [E]: ChET, CHOx } \\
\text { [Mol]: Covalent } \\
\text { [M]: Ampero. (DPV) vs } \\
\text { Ag/AgClk }\end{array}$ & 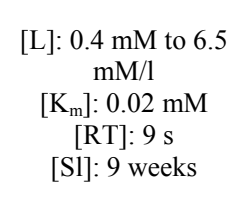 & $\begin{array}{c}\text { Basu et al. } \\
\text { [29] }\end{array}$ \\
\hline 9) & $\begin{array}{c}\text { [Mat]: Polypyrrole/PtNP } \\
\text { composite } \\
\text { [E]: ChET, CHOx } \\
\text { [Mol]: Covalent } \\
\text { [M]: Impedimetric vs } \\
\text { Ag/AgClk }\end{array}$ & 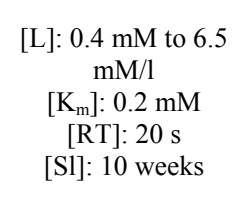 & $\begin{array}{l}\text { Present } \\
\text { work }\end{array}$ \\
\hline
\end{tabular}

ChOx-ChEt/PtNP/PPY/ITO nanobioelectrode is the enhanced electronic conductivity over PtNP/PPY/ITO, in spite of insulating nature of ChOx and ChEt which demonstrates that the nanobioelctrode offers an enzyme friendly microenvironment to retain the bioactivity of the enzyme system. The above nano bioelectrodes ChOx-
$\mathrm{ChEt} / \mathrm{PtNP} / \mathrm{PPY} / \mathrm{ITO}$ offer an excellent performance in terms of linearity, sensitivity, detection limit, response time and shelf life. This is attributed to the presence of PtNP along with PPY to enhance the overall biochemical reaction. The unique features of the ChOx-ChEt/PtNP/ PPY/ITO nanobioelectrode lie on the novelty of fabrication process, measurement technique, reusability, minimum interference and very low $K_{m}$ value. The limitation of the impedance measurement is the semi-logarithm relationship of the calibration curve and selection of the representative circuit from the various Nyquist plots.

\section{Acknowledgements}

We thank Dr. Ashok Kumar Chauhan (Founder President, Amity University Uttar Pradesh) for providing the facilities. We are thankful to Dr. R. P. Singh, Director, AINT, AUUP for interesting discussions. We acknowledge the financial assistance received from the Department of Biotechnology, Govt. of India (Project No BTPR 11123/ $\mathrm{MD} / 32 / 41 / 2008 \mathrm{DBT}$ ) for the financial support, India.

\section{REFERENCES}

[1] M. Nauck, W. Marz, J. Jarausch, H. Cobbaert, A. Sagers, D. Bernard. O. Delanghe, G. Honauer, P. Lehmann, E. Oestrich, A. Von Eckardstein, S. Walch, H. Wieland and G. Assmann, "Multicenter Evaluation of a Homogeneous assay for HDL-Cholesterol without Sample Pretreatment," Clinical Chemistry, Vol. 43, No. 9, 1997, pp. 1622-1629.

[2] P. Norouzi1, F. Faridbod, E. Nasli-Esfahan, B. Larijani and M. R. Ganjali, "Cholesterol Biosensor Based on MWCNTs- $\mathrm{MnO}_{2}$ Nanoparticles Using FFT Continuous Cyclic Voltammetry," International Journal Electrochemistry, Vol. 5, No. 7, 2010, pp. 1008-1017.

[3] Y. Chen and M. Gotoh, "Amperometric Needle-Type Glucose Sensor Based on a Modified Platinum Electrode with Diminished Response to Interfering Materials," Analytical Chimica Acta, Vol. 265, No. 1, 1992, pp. 5-14.

[4] Z. Xu, X. Chen and S. Dong, "Electrochemical Biosensors Based on Advanced Bioimmobilization Matrices," Trends in Analytical Chemistry, Vol. 25, No. 9, 2006, pp. 898-908. http://dx.doi.org/10.1016/j.trac.2006.04.008

[5] M. Tian, G. Wu and A. Chen, "Unique Electrochemical Catalytic Behavior of Pt Nanoparticles Deposited on $\mathrm{TiO}_{2}$ Nanotubes," American Chemical Society Catalyst, Vol. 2, 2012, pp. 425-432.

[6] A. N. Hendji, P. Bataillard and N. Jaffrezic-Renault, "Covalent Immobilization of Glucose Oxidase on Silanized Platinum Microelectrode for the Monitoring of Glucose," Sensors Actuators B, Vol. 15, 1993, pp. 127-134. http://dx.doi.org/10.1016/0925-4005(93)85038-C

[7] S. B. Hall, E. A. Khudaish and A. L. Hart, "Electrochemical Oxidation of Hydrogen Peroxide at Platinum Electrodes. Part V: Inhibition by Chloride," Electrochimica Acta, Vol. 45, No. 21, 2000, pp. 3573-3579. http://dx.doi.org/10.1016/S0013-4686(00)00481-3 
[8] M. Hepel, "The Electrocatalytic Oxidation of Methanol at Finely Dispersed Platinum Nanoparticles in Polypyrrole Films," Journal of Electrochemical Society, Vol. 145, No. 1, 1998, pp. 124-134. http://dx.doi.org/10.1149/1.1838224

[9] S. Mokrane, L. Makhlouf and N. Alonso-Vante, "Electrochemical Behaviour of Platinum Nanoparticles Supported on Polypyrrole (PPy)/C Composite," ECS Transaction, Vol. 6, 2008, pp. 93-103.

[10] S. S. Jeon, C. Kim, J. Ko and S. S. Im, "Pt Nanoparticles Supported on Polypyrrole Nanospheres as a Catalytic Counter Electrode for Dye-Sensitized Solar Cells," Journal of Physical Chemistry C, Vol. 115, No. 44, 2011, pp. 22035-22039. http://dx.doi.org/10.1021/jp206535c

[11] M. Yang, Y. Yang, H. Yang, G. Shen and R. N. Yu, "LayerBy-Layer Self-Assembled Multilayer Films of Carbon Nanotubes and Platinum Nanoparticles with Polyelectrolyte for the Fabrication of Biosensors," Biomaterials, Vol. 27, 2006, pp. 246-255. http://dx.doi.org/10.1016/j.biomaterials.2005.05.077

[12] H. Chen, R. Yuan, Y. Chai, J. Wang and W. Li, "Glucose Biosensor Based on Electrodeposited Platinum Nanoparticles and Three-Dimensional Porous Chitosan Membranes," Biotechnology Letter, Vol. 32, No. 10, 2010, pp. 1401-1404. http://dx.doi.org/10.1007/s10529-010-0303-Z

[13] R. Bittman, "Cholesterol: Its functional and Metabolism in Biology and Medicine," Plenum Press, New York, 1997. http://dx.doi.org/10.1007/978-1-4615-5901-6

[14] P. L. Yeagle, "Biology of Cholesterol," CRC Press, Boca Raton, 1998.

[15] C. F. Ana Maria, B. Oliveira, G. M. Helena and A. P. Piedade, "An Electrochemical Bienzyme Membrane Sensor for Free Cholesterol," Bioelectrochemistry Bioengineering, Vol. 28, 1992, pp. 105-115.

[16] T. Siao, Y. C. Chen and C. A. Lee, "Amperometric Cholesterol Biosensors Based on Carbon Nanotube-Chitosanplatinum-Cholesterol Oxidase Nanobiocomposite," Sensors Actuators B, Vol. 135, No. 1, 2008, pp. 96-101. http://dx.doi.org/10.1016/j.snb.2008.07.025

[17] S. Brahim, D. Narinesing and A. Guiseppi-Elie, "Amperometric Determination of Cholesterol in Serum Using a Biosensor of Cholesterol Oxidase Contained within a Polypyrrole-Hydrogel Membrane," Analytical Chimica Acta, Vol. 448, no. 1-2, 2001, pp. 27-36.

http://dx.doi.org/10.1016/S0003-2670(01)01321-6

[18] M. K. Ram, P. Bertoncello, H. Ding, S. Paddeu and C. Nicolini, "Cholesterol Biosensors Prepared by Layer-ByLayer Technique," Biosensors Bioelectronics, Vol. 16, No. 9, 2001, pp. 849-856. http://dx.doi.org/10.1016/S0956-5663(01)00208-1

[19] S. Brahim, D. Narinesing and A. Guiseppi-Elie, "Amperometric Determination of Cholesterol in Serum Using a Biosensor of Cholesterol Oxidase Contained within a Polypyrrole-Hydrogel Membrane," Analytical Chimica Acta, Vol. 448, 2001, pp. 27-36. http://dx.doi.org/10.1016/S0003-2670(01)01321-6

[20] M. L. Moraes, N. C. de Souza, O. H. Caio, F. Marystela, P. Ubirajara, F. Rodrigues, R. Antonio, Jr., Z. Valtencir and N. O. Osvaldo, Jr., "Immobilization of Cholesterol Oxidase in LBL Films and Detection of Cholesterol Using ac Measurements," Material Science Engineering C, Vol. 29, No. 2, 2009, pp. 442-447.

http://dx.doi.org/10.1016/j.msec.2008.08.040

[21] S. Singh, A. Chaubey and B. D. Malhotra, "Amperometric Cholesterol Biosensor Based on Immobilized Cholesterol Esterase and Cholesterol Oxidase on Conducting Polypyrrole Films," Analytical Chimica Acta, Vol. 502, No. 2, 2004, pp. 229-234. http://dx.doi.org/10.1016/j.aca.2003.09.064

[22] S. Suman, P. R. Solanki, M. K. Pandey and B. D. Malhotra, "Covalent Immobilization of Cholesterol Esterase and Cholesterol Oxidase on Polyaniline Films for Application to Cholesterol Biosensor," Analytical Chimica Acta, Vol. 568, No. 1-2, 2006, pp. 126-132. http://dx.doi.org/10.1016/j.aca.2005.10.008

[23] S. Singh, P. R. Solanki, M. K. Pandey and B. D. Malhotra, "Cholesterol Biosensor Based on Cholesterol Esterase, Cholesterol Oxidase and Peroxidase Immobilized onto Conducting Polyaniline Films," Sensors Actuators: B, Vol. 115, No. 1, 2006, pp. 534-541. http://dx.doi.org/10.1016/j.snb.2005.10.025

[24] G. Li, J. M. Liao, G. Q. Hu, N. Z. Ma and P. J. Wu, "Study of Carbon Nanotube Modified Biosensor for Monitoring Total Cholesterol in Blood," Biosenor and Bioelectronics, Vol. 20, No. 10, 2005, pp. 2140-2144. http://dx.doi.org/10.1016/j.bios.2004.09.005

[25] P. R. Solanki, A. Kaushik, A. A. Ansari, A. Tiwari and B. D. Malhotra, "Multi-Walled Carbon Nanotubes/Sol-GelDerived Silica/Chitosan Nanobiocomposite for Total Cholesterol Sensor," Sensors Actuators B, Vol. 137, No. 2, 2009 , pp. $727-735$. http://dx.doi.org/10.1016/j.snb.2008.12.044

[26] S. Aravamudhana, A. Kumarb, S. Mohapatra and S. Bhansali, "Sensitive Estimation of Total Cholesterol in Blood Using Au Nanowires Based Micro-Fluidic Platform," Biosensors and Bioelectronics, Vol. 22, No. 9-10, 2007, p. 2289.

http://dx.doi.org/10.1016/j.bios.2006.11.027

[27] S. K. Arya, P. Pandey, S. P. Singh, M. Datta and B. D. Malhotra, "Dithiobissuccinimidyl Propionate Self Assembled Monolayer Based Cholesterol Biosensor," Analyst, Vol. 132, No. 10, 2007, pp. 1005-109. http://dx.doi.org/10.1039/b707000d

[28] S. K. Arya, M. Datta, S. P. Singh and B. D. Malhotra, "Biosensor for Total Cholesterol Estimation Using N-(2Aminoethyl)-3-aminopropyltrimethoxysilane Self-Assembled Monolayer," Analytical Bioanalytical Chemistry, Vol. 389, 2007, pp. 2235-2242. http://dx.doi.org/10.1007/s00216-007-1655-7

[29] K. Singh, P. R. Solanki, T. Basu and B. D. Malhotra, "Polypyrrole/Multiwalled Carbon Nanotubes Based Biosensor for Cholesterol Estimation," Polymers for Advanced Techniques, Vol. 23, No. 7, 2011, pp. 1084-1091. http://dx.doi.org/10.1002/pat.2020

[30] R. Chauhan, Deepshikha and T. Basu, "Development of a Reusable Transducer Matrice Based on Nano Structured Based on Nano Structured Conducting Polyaniline and Its 
Application to Cholesterol Biosensor," Science for Advanced Material, Vol. 4, No. 1, 2012, pp. 96-125. http://dx.doi.org/10.1166/sam.2012.1256

[31] J. R. Macdonald, "Impedance Spectroscopy," Wiley Interscience Publication, New York, 1987

[32] M. I. Prodromidis, "Impedimetric Biosensors and Immunosensors," Pakistan Journal of Analytical Environmental Chemistry, Vol. 8, 2007, pp. 69-71.

[33] K. Singh, T. Basu, P. R. Solanki and B. D. Malhotra, "Poly(pyrrole-co- $N$-methyl pyrrole) for Application to Cholesterol Sensor," Journal Material Science, Vol. 44, No. 4, 2009, pp. 954-961. http://dx.doi.org/10.1007/s10853-008-3184-y

[34] T. K. Vishnuvardhan, V. R. Kulkarni, C. Basavaraja and S. C. Raghavendra, "Synthesis, Characterization and a.c. Conductivity of Polypyrrole $/ \mathrm{Y}_{2} \mathrm{O}_{3}$ Composites, Bulletin," Material Science, Vol. 29, No. 1, 2006, pp. 77-83.

[35] C. Dhand, S. K. Arya, M. Datta and B. D. Malhotra, "Polyaniline-Carbon Nanotube Composite Film for Cholesterol Biosensor," Analytical Biochemistry, Vol. 383, No. 2, 2008, pp. 194-199. http://dx.doi.org/10.1016/j.ab.2008.08.039

[36] V. Nandakumara, J. T. La Belle, J. Reed, M. Shah, D. Cochran, L. Joshi and T. L. Alford, "A Methodology for Rapid Detection of Salmonella typhimurium Using Label-
Free Electrochemical Impedance Spectroscopy," Biosenors Bioelectronics, Vol. 24, No. 4, 2008, pp. 1039-1042. http://dx.doi.org/10.1016/j.bios.2008.06.036

[37] J. G. Guan, Y. Q. Miao and Q. J. Zhang, "Impedimetric biosensors," Journal of Biosensor and Bioengineering, Vol. 97, No. 4, 2004, pp. 219-226,

[38] J. S. Daniels and N. Pourmand, "Label-Free Impedance Biosensors: Opportunities and Challenges," Electroanalysis, Vol. 19, No. 12, 2007, pp. 1239-1257. http://dx.doi.org/10.1002/elan.200603855

[39] Y. S. Fung and Y. Y. Wong, "Self-Assembled Monolayers as the Coating in a Quartz Piezoelectric Crystal Immunosensor to Detect Salmonella in Aqueous Solution," Analytical Chemistry, Vol. 73, No. 21, 2001, pp. 53025309. http://dx.doi.org/10.1021/ac010655y

[40] C. E. H. Berger and J. Greve, "Differential SPR Im- munosensing," Sensors Actuators B, Vol. 63, No. 1, 2000, pp. 103-108 http://dx.doi.org/10.1016/S0925-4005(00)00307-5

[41] A. Kaushik, P. R. Solanki, K. Kaneto, C. G. Kim, S. Ahmad and B. D. Malhotra, "Nanostructured Iron Oxide Platform for Impedimetric Cholesterol Detection," Electroanalysis, Vol. 22, No. 10, 2010, pp. 1045-1055 http://dx.doi.org/10.1002/elan.200900468 